\title{
THE ADSORPTION OF BENZENE, TOLUENE AND ETHYLBENZENE ON SOILS NEAR INFINITE DILUTION
}

\author{
Chih-yu Chen ${ }^{*}$ and Shian-chee Wu \\ Graduate Institute of Environmental Engineering, National Taiwan University, \\ Taipei, 10670, Taiwan, R. O. C. \\ (Received in Germany 13 March 1995; accepted 6 September 1995)
}

\begin{abstract}
The inverse gas chromatography method was used to study the adsorption phenomena of volatile organic compounds (VOCs) onto the soils in the Henry's law region. From the retention time obtained experimentally the partition coefficients and some thermodynamic parameters were estimated. It was found that the adsorption processes of VOCs onto larger soil particle were affected by intraparticle mass transfer. The pattern of the contribution of specific interactive forces was proven to play an important role on the adsorption processes. And the lower partition coefficient for ethylbenzene onto diluvium red soils was attributed to the sieving effect of soils against larger VOC molecules and the weaker specific interaction between sorbate and sorbent.
\end{abstract}

\section{Introduction}

Many soils were contaminated with volatile organic compounds (VOCs) as a result of the improper design of hazardous waste disposal facilities, accidental spills, leaky under-ground storage tanks, pipes and so on. Most of these contaminants have been demonstrated having adverse effects on human health. In recent years increasing attempts have been made to better understand the fate of VOCs in the vadose zone or evacuated contaminated soil piles in order to assess the environmental impact of these contaminants and to predict the performance of soilpurging remedial action. There are many processes that influence the movement of VOCs in the soils such as advection, dispersion, molecular diffusion, volatilization, and adsorption. Adsorption is one of the most important processes affecting the fate of VOCs in the soil column. Also, the transfer mechanisms controlling the release of VOC from a contaminated soil zone or from a soil being purged during a clean-up process must be carefully studied and parameterized in order to establish a predictive model to support the designing and implementing a remedial action. To better understand the adsorption phenomena of VOCs on soils is necessary for evaluating the environmental impacts and/or choosing proper remediation actions.

Soils are porous media created at the land surface by weathering processes derived from biological, geological, and hydrological phenomena ${ }^{1}$. It may be taken for granted that the solid phase of soils are extraordinary adsorbents in adsorption of VOCs. Many models and mechanisms have been proposed to explain the sorption phenomena, for instance, linear partitioning, langmuir surface adsorption, BET multilayer adsorption, staticelectric attraction, polar-polar interaction and so $\mathrm{on}^{2}$. However, probably due to the complicated properties and heterogeneity of the soil surface there is no single mechanism could be used to describe the variable sorption processes. Surface heterogeneity plays an important role in the adsorption processes ${ }^{3}$. The main sources of surface heterogeneity are the following: different types of crystal planes, growth steps, crystal edges coners, scattered organic matter,corners, various atoms and functional groups exposed at the surface and available for adsorption, irregularities in crystallographic structure of a surface and impurities strongly bounded with the surface.

Inverse gas chromatography (IGC) is a useful tool for studying the gas-solid interface as this method can provide information about the adsorption on different types of solid surfaces ${ }^{4-7}$. Thermodynamic parameters of 
adsorption and the surface energy of solids can be measured using IGC at infinite dilution. Unlike conventional adsorption techniques, IGC measures the adsorption data under very low vapor concentration condition, where the surface coverage approaches zero and adsorbate-adsorbate interactions are negligible. And the observed thermodynamic behavoirs depends only on adsorbate-adsorbent interactions. Although many studies were done with adsorbents such as carbon fiber, active carbon, graphite and so on to survey their surfaces and thermodynamic parameters of adsorption, only few researchers used the IGC method to study the adsorption phenomena of soils .

The purpose of this study is to relate the thermodynamic parameters of adsorption to the properties of soils. The adsorption of benzene, toluene and ethylbenzene on soils of different sources and particle sizes was investigated by using IGC and the corresponding partition coefficients were then calculated. The thermodynamics of adsorption was studied by varying the column temperature. The phenomena of mass transfer hindrance will be examined and discussed.

\section{Background and Theory}

Thermodynamics of sorption. Sorption processes are the results of a collection of different types of surface reactions including binding by dispersive van der Waals force, electrical attractions, complexation, formation of covalent bonds and others. The thermodynamic behavior of sorption reveal some information about the sorption mechanisms. When adsorption equilibrium took place at infinite dilution (zero surface coverage), the adsorbateadsorbate lateral interactions were negligible, and the thermodynamic parameters depend only on adsorbateadsorbent interactions. If $n_{s}$ was moles adsorbed on the packing material in a GC column, $n_{g}$ was moles of adsorbate in the mobile gas phase, $A$ was the total surface area of adsorbent and $V_{c o l}$ was the void volume in the column, Meyer ${ }^{8}$ proposed that

$$
k=\frac{n_{s} / A}{n_{g} R T / V_{\text {col }}}=\frac{V_{c o l}}{A R T} \frac{n_{s}}{n_{g}}
$$

so that $k$ the ratio of surface concentration of sorbate on adsorbed phase and partial pressure of sorbate in gas phase, was the partition coefficient of adsorbate between adsorbent and gas phase at equilibrium. The retention time for a gaseous compound through the column is the fundamental parameter measured in gas chromatography and it is essential to link the retention time with the partition coefficient. If a molecule spends half its time in mobile phase, it takes twice as long to elute as a molecule which spends all of its time there. Thus

$$
t_{r}=\frac{t_{o}}{n_{g} /\left(n_{g}+n_{s}\right)}=t_{o}\left(1+\frac{n_{s}}{n_{g}}\right)
$$

and

$$
n_{s} / n_{g}=\left(t_{r}-t_{o}\right) / t_{o}
$$

Where $t_{r}$ and $t_{o}$ are the retention time of adsorbate and carrier gas, respectively. Substituted into eqn. (1), eqn. (1) becomes

$$
k=\frac{V_{c o d}}{A R T} \frac{\left(t_{r}-t_{o}\right)}{t_{o}}=\frac{f}{A R T}\left(t_{r}-t_{o}\right)=V_{s} / R T
$$

where $f=V_{c o} / t_{o}$ is the flow rate at that condition and $V_{s}=f\left(t_{r}-t_{o}\right) / A$ is the specific net retention volume.

Meyer ${ }^{8}$ proposed that the standard free energy of adsorption of transferring one mole of vapor from the gas phase at pressure $p^{o}$ to an adsorbed state described by a spreading pressure $\pi$ is

$$
\Delta G^{o}=R T \ln \left(\pi / P^{o} V_{s}\right)=R T \ln \left(\pi / P^{o} k R T\right)
$$


There are two frequently used surface standard state to be chosen: the Kemball-Rideal definition $(\pi=0.0608$ dynes $/ \mathrm{cm}, p^{o}=1.013 \times 10^{6}$ dynes $\left./ \mathrm{cm}^{2}\right)$ and deBoer definition $\left(\pi=0.338\right.$ dynes $/ \mathrm{cm}, p^{o}=1.013 \times 10^{6}$ dynes $/ \mathrm{cm}^{2}$ ). The value of $\Delta G^{0}$ clearly depends on the choice of surface standard state. The $\Delta H^{\circ}$ for the same standard process can be calculated by using the Gibbs-Helmholtz equation and yield

$$
\frac{\Delta H^{0}}{T^{2}}=\frac{R d \ln \left(V_{S}\right)}{d T}
$$

A plot of $\ln \left(V_{s}\right)$ versus $V T$ yields a line whose slope is $-\Delta H^{\circ} / R . \Delta H^{\circ}$ is usually assumed independent of temperature and the value of $\Delta H^{\circ}$ does not rely on the choice of $\pi$ for the standard surface state. From the difference between $\Delta H^{\circ}$ and $\Delta G^{\circ}$, the standard entropy of adsorption of the adsorbate at infinite dilution, can be calculated:

$$
\Delta S^{0}=\left(\Delta H^{0}-\Delta G^{0}\right) / T
$$

Similar to $\Delta G^{o}$ the value of $\Delta S^{o}$ is affected by the choice of standard surface state.

Mass transfer in the soil column. It takes a very short time for a surface adsorption reaction. However, it may take quite long time for a sorbate molecule transfer from a compartment to another compartment, for example, from bulk inter-pore space to the inside of a soil aggregate or from gas phase to the soil surface. The mass-transfer hindrance effects can be identified from some sorption phenomena during soil column experiments, for instance, skewed breakthrough concentration profile, and delay of the appearance of the concentration peak 9 .

Aggregation of soil materials is a fundamental nature of soils. The diffusion of sorbate in the intraparticle pores could take quite long time, therefore, retard the sorption process 10 . The extent of the significance of the intraparticle diffusion depends on many aggregate properties and flow conditions. Equilibrium can not be reached if the time scale of the variation of the concentration in bulk flow is shorter than the time scale of intraparticle traveling. For larger aggregates the nonequilibrium phenomenon will be more obvious due to longer path of intraparticle diffusion.

\section{Experimental section}

Gas Chromatography Stationary Phase. There were two kinds of soils used in this study, slate alluvial soils and diluvium red soils. The soils were air-dried for about one month and then ground by a wooden hammer. The ground soils were sieved and the fractions with particle diameter smaller than 20 mesh were collected for further use. Several basic properties of this two kinds of soils were analyzed. The moisture content of the air-dried soil was determined gravimetrically (oven-drying at $103.5^{\circ} \mathrm{C}$ for $24 \mathrm{hr}$ ). The soil-pH was measured in a 1:1 (w/w) solid-deionized water mixture11. The organic carbon content of the soil was obtained by using the Walkley-Black procedure ${ }^{12}$. The cation-exchange capacity (CEC) of the soil was determined with the method proposed by Rhoades ${ }^{13}$. The specific surface area of the soils was determined by BET nitrogen adsorption method with a porosimeter(Micromeritics Instrument Corporation, ASAP2000). The basic properties of soils were listed in Table I.

The soils collected were divided into three sections according to particle diameter, 20/60 mesh, 60/100 mesh and smaller than 100 mesh. The samples were introduced into a glass column $4 \mathrm{~mm}$ in internal diameter and $10 \mathrm{~cm}$ in length. The column were packed with soils at an amount of soils about $0.5 \mathrm{~g}$. Then the column was put into the oven of gas chromatography. Prior to experiments the column was conditioned for $24 \mathrm{hr}$ at $553 \mathrm{~K}$ with a flow of nitrogen.

Sorbates. All sorbates were analytical grade. Benzene and ethyl benzene were obtained from Riedel-deHaen Corp. and toluene from Merck. And all sorbate samples were prepared in the form of vapor by diluting the saturated 
vapor of each sorbate liquid with nitrogen gas. To approach the assumption of infinite dilution, the concentration of sorbate was low enough to result in a very small signal from FID only.

Table I. The basic properties of soils.

\begin{tabular}{lll}
\hline & slate alluvial soils & diluvium red soils \\
\cline { 2 - 3 } soil fraction,\% & & \\
$\quad$ clay & 35 & 23 \\
$\quad$ silt & 40 & 35 \\
$\quad$ sand & 25 & 42 \\
pH & 6.79 & 4.26 \\
CEC, cmol(+)/Kg & 6.0 & 3.4 \\
organic carbon content, \% & & \\
20-60 mesh & 0.87 & 1.38 \\
60-100 mesh & 0.86 & 1.64 \\
$<100$ mesh & 1.14 & 1.56 \\
moisture content, \% & 1.28 & 2.76 \\
specific surface area, $\mathrm{m}^{2} / \mathrm{g}$ & 9.57 & 30.6 \\
(BET/N2) & &
\end{tabular}

GC Apparatus and Measurement. Inverse gas chromatography (IGC) at infinite dilution measurements were performed with a Hewlett-Packard 5890A gas chromatography equipped with a flame-ionization detector. The ultra-high-purity nitrogen carrier gas was passed through $4 \mathrm{~A}$ molecular sieve. Flow rate was measured at the outlet of the detector with a calibrated soap-film flowmeter and it was measured after each run of different temperature. The experiments were carried out under the following conditions: the flow rate of carrier gas $\left(\mathrm{N}_{2}\right)$ was between 5 and $10 \mathrm{ml} / \mathrm{min}$, and the temperatures were in the range of 493-533 K. Hydrocarbons in the form of vapor were injected into the injector of gas chromatography with a gas-tighted syringe (Hamilton). The dead volumes of the system were determined by injecting indoor air simultaneously with the sorbates. Retention of air on the column was neglected and no variation with temperature was observed. All peaks were recorded on a Hewlett-Packard 3392A integrator. The peaks at infinite dilution were slightly skewed and the retention time for the symmetrical peaks was taken at the peak maxima.

\section{Results and Discussion}

Partition coefficient. Theoretically, the net retention time of peak does not depend on the injection size under the condition of infinite dilution. And the specific net retention volume $\left(V_{s}\right.$, in meter) were essentially independent of flow rate under the equilibrium conditions. From eq 4 the partition coefficient $k$ could be calculated. But the definition of $k$ mentioned above was seldom used on usual occasions. Here a new parameter $\kappa_{s}$, which represents the ratio of amounts of solute in sorbed phase by unit surface area and in gas phase by unit volume, was quoted to replace the $k$ as partition coefficient. And the relationship between $K_{s}$ and $k$ is

$$
K_{s}=k R T=V_{s}
$$

At least three measurements of specific net retention volume were conducted to calculate each partition coefficient. The reproducibility was good with a percent standard deviation less than $3 \%$ in each case. However, because of the errors arising from flow rate measurement, the estimation of dead volume of the column, slight temperature variations during the experiments, and the uncertainty in the surface area measurements, the overall precision of $\kappa_{s}$ 
was little lower.

The partition coefficients, $K_{s}$ (in meter) in Henry's law region at different conditions are listed in Table II. Obviously the partition coefficient of each case decreased with increasing temperature. It indicated that the adsorption processes of these three compounds on soils was exothermic. And it was predicted that at room temperature the partition coefficient would be very large. The partition coefficients of these three adsorbate on slate alluvial soils were larger than that on diluvium red soils. Both the organic carbon content and specific surface area (by $\mathrm{N}_{2} / \mathrm{BET}$ method) of diluvium red soil were larger than those of slate alluvial soil. Since $k$ represents the ratio of surface activity and vapor phase pressure the available surface area is not relevant as well as the BET surface. Organic matter and mineral surface may play positive or negative role on the enhancement of sorption depending on its relative affinity to the sorbate comparing to that of other types of surfaces.

Table II. Partition coefficient for benzene, toluene, and ethylbenzene on soils.

\begin{tabular}{|c|c|c|c|c|}
\hline \multirow[b]{2}{*}{ adsorbent } & \multirow{2}{*}{$\begin{array}{l}\text { Temp. } \\
\text { (K) }\end{array}$} & \multicolumn{3}{|c|}{$\mathrm{K}_{\mathrm{s}} \times 10^{6}(\mathrm{~m})$} \\
\hline & & Benzene & Toluene & Ethylbenzene \\
\hline \multirow{5}{*}{$\begin{array}{l}\text { slate alluvial soil } \\
<100 \text { mesh }\end{array}$} & 513 & $3.45(33.0)$ & -.--- & $-\cdots$ \\
\hline & 523 & $1.81(17.3)$ & -..-- & $\cdots$ \\
\hline & 533 & $1.48(14.2)$ & $4.65(44.5)$ & $34.2(327.3)$ \\
\hline & 543 & ...-- & $3.10(29.7)$ & $18.9(180.9)$ \\
\hline & 553 & ----- & $1.91(18.3)$ & $10.8(103.4)$ \\
\hline \multirow{4}{*}{$\begin{array}{l}\text { diluvium red soil } \\
<100 \text { mesh }\end{array}$} & 513 & $0.21(6.4)$ & $1.83(56.0)$ & -.-- \\
\hline & 523 & $0.14(4.3)$ & $1.08(33.0)$ & $0.79(24.2)$ \\
\hline & 533 & $0.10(3.1)$ & $0.70(21.4)$ & $0.59(18.1)$ \\
\hline & 543 & ----- & -..-- & $0.42(12.9)$ \\
\hline
\end{tabular}

* the values in parentheses are partition coefficient in unit of $\mathrm{m}^{3} / \mathrm{g}$.

Some researcher ${ }^{14-15}$ proposed that the adsorption processes were strongly influenced by the chemical nature, pore size and pore shape of the adsorbent. Seri-Levy and Avnir ${ }^{16}$ also pointed out that the heterogeneous surface geometry also affected the adsorption processes. To explain the variation of observed partition coefficients in this study, the concept of a varying distribution function of adsorption energy was proposed. The complicated chemical composition and porous characteristics resulted in surface energetic heterogeneity of a adsorbent, therefore, each adsorbent-adsorbate couple had its own function of adsorption energy 17-18. It meant that since there were many different kinds of adsorption sites on the soils, the adsorption energy of each site were different when adsorption took place and there existed distribution function which described the adsorption energy of different adsorption sites. When the adsorption energy between site and adsorbate was large enough to bind the adsorbate onto the site within the experimental regime, it was said that the site was 'effective'. The higher the temperature, the more the adsorption energy was needed to bind the adsorbate onto the soil surface. Most of the adsorption sites were 'effective' when adsorption took place at low temperature, and only part of sites were 'effective' at high temperature. So, partition coefficient decreased with increasing temperature. From the observation that the partition coefficients of these three adsorbate on slate alluvial soils were larger than that on diluvium red soils. It was assumed that on unit surface area the number of 'effective' sites on slate alluvial soils was much more than those on diluvium red soils at the same conditions. But the relationship between the number of 
'effective' site and the basic properties of soils is also unclear.

The results of specific net retention volume $\left(V_{s}\right)$ versus number of carbon atoms at $533 \mathrm{~K}$, except for the adsorption of benzene (at $523 \mathrm{~K}$ ) and ethylbenzene (at $543 \mathrm{~K}$ ) on slate alluvial soils with particle size $60-100$ mesh, were shown in Figure 1. For the same conditions the partition coefficient increased with increasing molecular weight of adsorbate, except for the adsorption of ethylbenzene on diluvium red soils. On diluvium red soils the partition coefficient of ethylbenzene was slightly smaller than that of toluene. In general, the interaction force increased with increasing the molecular weight of adsorbate. The reason of lower $V_{s}$ and $\kappa_{s}$ for ethylbenzene might be resulted from the molecular sieving effect of soils or the smaller specific interaction between ethylbenzene and diluvium red soils. Previous study had proven the existence of molecular sieving effects on porous active carbons $\mathbf{5}^{5}$. Here, it was proposed that there seemed to exist molecular sieving effects on diluvium red soils, hence the partition coefficient of ethylbenzene on diluvium red soils was smaller that of toluene. From the observation of this study, it was suggested that the influence of geometric factors, such as pore size and pore shape, on adsorption processes might be significant. When penetrating the soil particles, smaller adsorbates (toluene, benzene) entered into the micropores, adsorbed, desorbed and then went out, and the larger adsorbates (ethylbenzene) could not enter into the micropores which smaller adsorbates could. For smaller adsorbate it needed much more time to penetrate the soil particle and the partition coefficient calculated from specific net retention volume was larger than that of adsorbate sieved by adsorbent. So the 'effective' sites used for larger adsorbate adsorbing decreased sharply. According to the concept of the 'effective' site proposed before, the phenomena of loweredpartition coefficient could be explained.

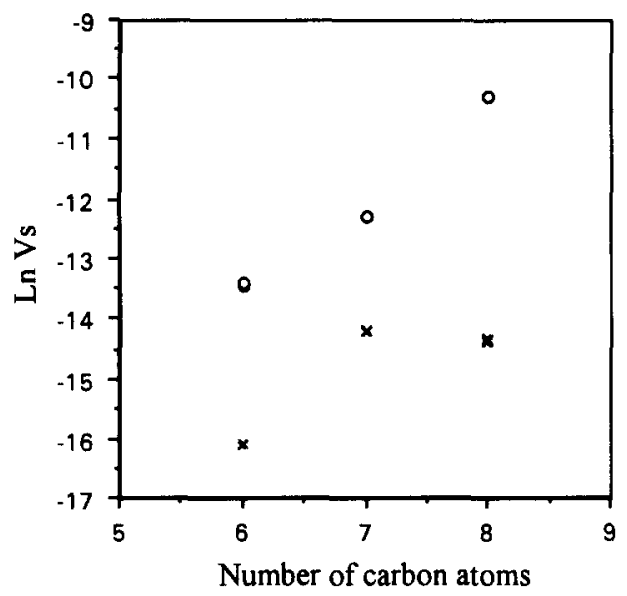

Fig. 1. Specific net retention volume vs number of carbon atoms of the probe benzene, toluene and ethylbenzene for different soils at $533 \mathrm{~K}$.

- slate alluvial soils $<100$ mesh

* diluvium red soils $<100$ mesh

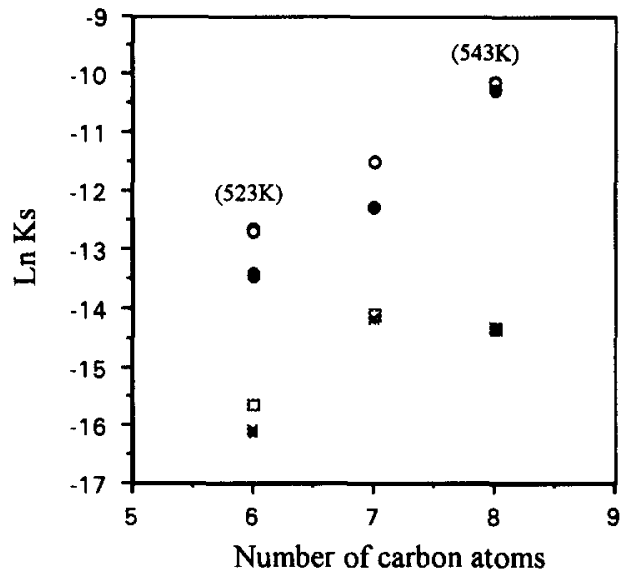

Fig. 2. Partition coefficient vs number of carbon atoms of the probe benzene, toluene and ethylbenzene for different soils at $533 \mathrm{~K}$.
- slate alluvial soils 60-100 mesh
- slatealluvial soils $<100$ mesh
a diluvium red soils 60-100 mesh
* diluvium red soils $<100$ mesh

Mass transfer hindrance. It was interesting to find that the partition coefficient slightly decreased with decreasing particle size of soils under the same conditions. In Figure 2 , the values of the partition coefficients $\left(K_{s}\right)$ at $533 \mathrm{~K}$ versus the number of carbon atoms, except for benzene at $523 \mathrm{~K}$ and ethylbenzene at $543 \mathrm{~K}$ on slate alluvial soils 
with particle size 60-100 mesh, were plotted. For different particle sizes the difference of $K_{s}$ on slate alluvial soils was marked, but it was not significant for toluene and ethylbenzene on diluvium red soils. The movement of adsorbate in soil column were controlled by the rate of adsorption-desorption reaction and intraparticle mass transfer. If the rate of adsorption or desorption reaction was the controlling step in adsorption processes, the partition coefficient would be same for different particle size. Wu and Gschwend 10 had discussed the effects of intraparticle mass transfer on the transport of solute in sediment. Keytes and Silcox ${ }^{\mathbf{1 9}}$ had observed that the ratecontrolling mechanism of desorption reaction and intraparticle mass transfer had close relationship. And they found that the desorption rate of VOCs from large particles was slower than that from small particles. From the results of our experiments, it could be concluded that intraparticle mass transfer might play a significant role in the adsorption processes of VOCs on soils. Though the particle size was different, the partition coefficients were about equivalent for both toluene and ethylbenzene on diluvium red soils. It seems apparent that the effects of intraparticle mass transfer could be ignored in that condition, and the controlling step in the adsorption processes was adsorptiondesorption reaction.

Thermodynamics of sorption. In previous studies about IGC method the effects of intraparticle mass transfer had not been mentioned detailly. To compare the discrepancy of the sorption behaviors of these two soils, in this study it was assumed that the adsorption processes took place on particle size smaller than 100 mesh were considered to be controlled mainly by adsorption-desorption reaction. Based on this assumption, the thermodynamic parameters can be obtained from specific net retention volume when adsorption took place near infinite dilution. By using equation. 5, the standard free energy of adsorption for transferring one mole of vapor from the gas phase at pressure $p^{0}$ to an adsorbed state described by a spreading pressure $\pi$ can be calculated, if the value of $p^{0}$ and $\pi$ were known. In this study the deBoer definition $\left(\pi=0.338\right.$ dynes $\left./ \mathrm{cm}, \rho^{0}=1.013 \times 10^{6} \mathrm{dynes} / \mathrm{cm}^{2}\right)$ was used to calculate standard free energy and the results were listed in Table III.

Table III. The thermodynamic parameters of different cases. $(533 \mathrm{~K})$

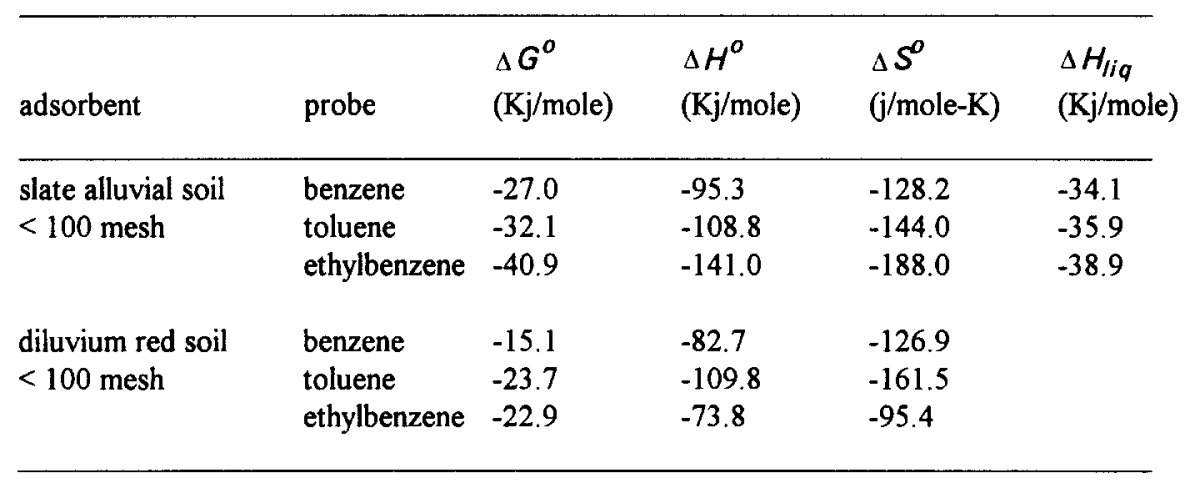

The other two standard thermodynamic parameters of adsorption, enthalpy and entropy, were calculated by using eqs 6 and 7. From the temperature dependence of $\ln \left(V_{s}\right)$ (Figure 3 and 4) the standard enthalpy of adsorption $\Delta H^{\circ}$ can be calculated. Once $\Delta H^{o}$ and $\Delta G^{\circ}$ were known, the value of standard entropy of adsorption $\Delta S^{\circ}$ was calculated. The values obtained for all samples at $533 \mathrm{~K}$ were listed in Table III and the heats of liquefaction of these three probes were listed also. Table IV lists the results of other studies and it is also obvious that the value of thermodynamic parameters depend on the the properties of adsorbent and adsorbate. 
Table IV. The difference of thermodynamic parameters for different adsorbate-adsorbent pairs.

\begin{tabular}{|c|c|c|c|c|c|c|}
\hline adsorbate & adsorbent & $\begin{array}{l}\text { Temp. } \\
(\mathrm{K})\end{array}$ & $\begin{array}{l}\Delta G^{\circ} \\
(\mathrm{kJ} / \text { mole })\end{array}$ & $\begin{array}{l}\Delta H^{o} \\
(\mathrm{~kJ} / \mathrm{mole})\end{array}$ & $\begin{array}{l}\Delta S^{o} \\
(\mathrm{~J} / \mathrm{mole} / \mathrm{K})\end{array}$ & reference \\
\hline n-hexane & graphitized & 333 & -20.9 & -33.8 & -28.7 & a \\
\hline n-heptane & carbon black & $"$ & -25.1 & -39.2 & -42.3 & \\
\hline n-octane & & $"$ & -29.2 & -44.2 & -45.0 & \\
\hline n-butane & active carbon & 473 & -14.07 & -27.04 & -27.19 & b \\
\hline n-pentane & $"$ & $"$ & -17.86 & -52.39 & -72.39 & \\
\hline n-hexane & $"$ & $"$ & -21.9 & -75.93 & -113.26 & \\
\hline n-heptane & $"$ & $"$ & -26.03 & -97.77 & -150.41 & \\
\hline n-nonane & carbon fiber & 323 & -22.6 & -49.6 & -83.6 & c \\
\hline n-decane & " & " & -25.6 & -55.4 & -92.2 & \\
\hline n-undecane & $"$ & $"$ & -28.6 & -61.1 & -101 & \\
\hline n-dodecane & $"$ & $"$ & -31.6 & -66.8 & -109 & \\
\hline n-tridecane & $"$ & $"$ & -34.8 & -72.5 & -117 & \\
\hline
\end{tabular}

a:Domingo-García et al.,1984. b:López-Garzón et al., 1993. c:Vukov \& Gray, 1988.

To clearly understand the relationship, the thermodynamic parameters was plotted versus the number of carbon atoms of the adsorbate as shown in Figure 5 and Figure 6 . When linear hydrocarbons and general adsorbent such as active carbon were considered, linear relationship for the thermodynamic parameters vs the number of carbon atoms was obtained 5 . Nevertheless, the linear relationship did not exist here when benzene, toluene and ethylbenzene as probes and soils as adsorbent. The interaction between them was not as simple as that between linear hydrocarbons and general adsorbent. From the results observed there was significant difference in thermodynamic parameters for the three adsorbate on slate alluvial soils and diluvium red soils. The standard free energy for transferring one mole adsorbate from gas phase to sorbed phase in diluvium red soils was smaller than in slate alluvial soils. But this phenomenon and the basic properties of these two soils had no close relationship.

The enthalpy of adsorption of these three compounds were higher than their heats of liquefaction. It meant that the adsorbate-adsorbent interactions were stronger than the adsorbate-adsorbate interactions. The heat of adsorption $\left(-\Delta H^{\circ}\right)$ increased with increasing number of carbon atoms in slate alluvial soils, but it did not happen in diluvium red soils. The heat of adsorption for ethylbenzene adsorbed onto diluvium red soils was the smallest among these three adsorbates. The interaction between an adsorbate and an adsorbent consisted of two components, one dispersive and the other specific force. The former is the contribution of dispersion forces and the latter represents the contribution of other forces, such as hydrogen, polar and acid-base interaction. The difference between the enthalpy of adsorption and the heat of liquefaction was contributed by the difference of dispersive and specific components. The adsorption of saturated normal alkanes by an adsorbent involved mainly dispersive force and was assumed to be proportional to the molecular weight of adsorbate ${ }^{20}$. For these three adsorbates adsorbed onto identical adsorbent, the dispersive component should be about equivalent. From the observations of this study it was concluded that the specific component must play an important role on the adsorption of benzene compounds on soils. 


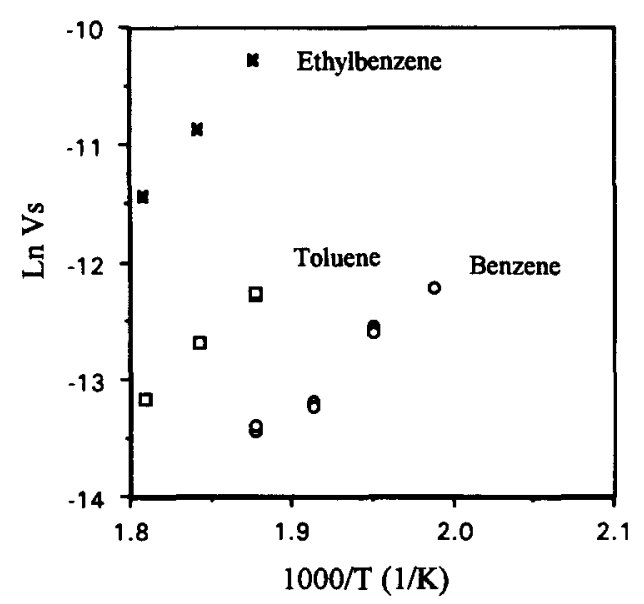

Fig. 3. LnVs vs $1000 / \mathrm{T}$ for benzene, toluene and ethylbenzene adsorbed onto slate alluvial soils smaller than 100 mesh.

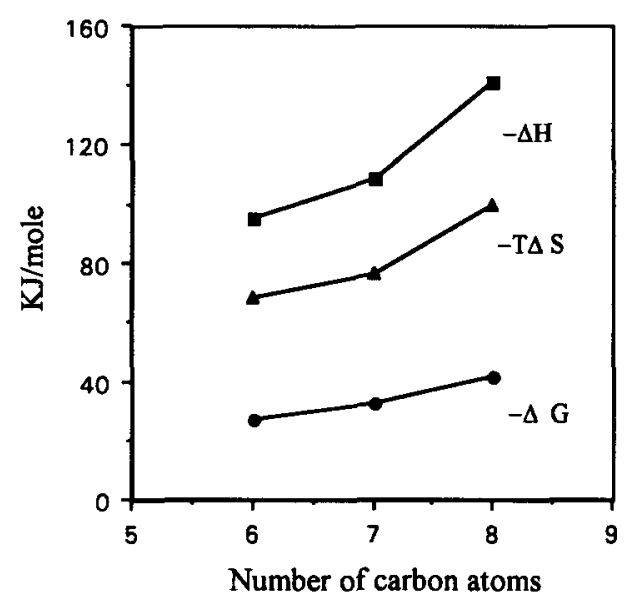

Fig. 5. Thermodynamic functions of adsorption vs. number of carbon atoms of the probes. The particle size of slate alluvial soils is smaller than 100 mesh.

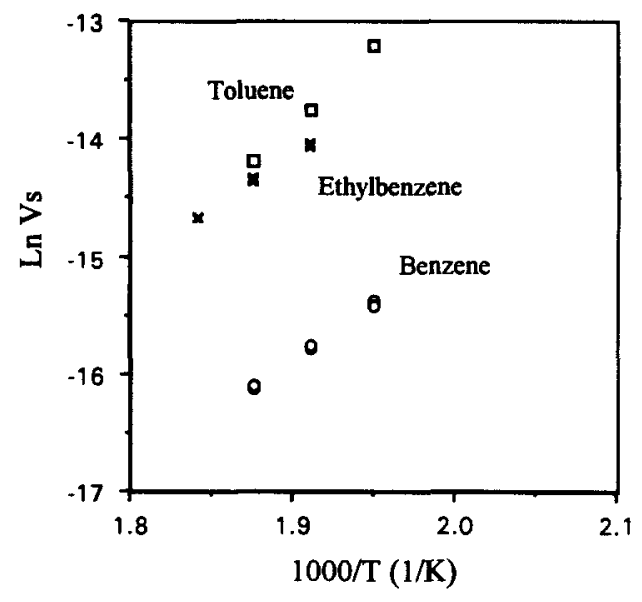

Fig. 4. LnVs vs $1000 / \mathrm{T}$ for benzene, toluene and ethylbenzene adsorbed onto diluvium red soils smaller than 100 mesh.

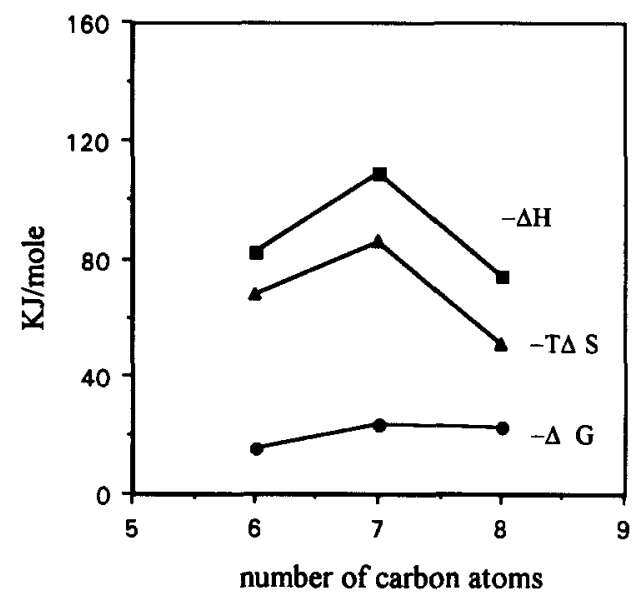

Fig. 6. Thermodynamic functions of adsorption vs. number of carbon atoms of the probes. The particle size of diluvium red soils is smaller than 100 mesh.

Table V. $\Delta S^{0}\left(\mathrm{~J} \mathrm{~K}^{-1} \mathrm{~mol}^{-1}\right)$ of benzene compounds on soils at $533 \mathrm{~K}$.

\begin{tabular}{llll}
\hline adsorbent & benzene & \multicolumn{1}{l}{ tolueneethylbenzene } \\
\hline & & experimental \\
slate alluvial soils & -128.2 & -144.0 & -188.0 \\
diluvium red soils & -126.9 & -161.5 & -95.4 \\
& & & \\
& & calculated & \\
& -53.9 & -54.6 & -55.1
\end{tabular}


Standard entropies of adsorption obtained by experiments as well as theoretically predicted are shown in Table V. The latter were calculated from the difference between the three-dimensional translational entropy of the adsorbate as an ideal gas and the entropy of the adsorbate as an ideal, mobile two-dimensional gas. Here the calculating method mentioned previously 4 were used to predict the entropy loss. It was apparent that the entropy loss was higher than that predicted by deBoer's model. And the entropy loss of one translational degree of freedom did not match the values obtained experimentally. So the discrepancy probably resulted from the rotational and conformational entropy loss. For ethylbenzene adsorbed by diluvium red soils the extent of specific interaction was lower and the entropy loss was smaller than that of other two adsorbates.

\section{Conclusion}

Inverse gas chromatography has been shown to be an efficient method for studying the adsorption of benzene compounds onto soils in the Henry's law region. And the partition coefficients calculated by specific net retention time decreased with increasing temperature. It meant that the adsorption of VOCs by soils was an exothermic process. The basic properties of soils such as specific surface area and organic carbon content did not adequately explain the results of partition coefficient. Under the condition of infinite dilution the adsorption processes of soils depended mainly on their chemical nature, pore size distribution and pore shape, especially on the microporous structures. From the results of different particle size it was found that the intraparticle mass transfer controlled the adsorption of larger particle.

The results of thermodynamic parameters showed that the adsorption processes had a very close relationship with the nature of adsorbate and adsorbent. Owing to that heat of adsorption for ethylbenzene onto diluvium red soils was lower than toluene and benzene, it was concluded that the specific component of interaction between adsorbate and adsorbent played an important role on the adsorption of soils. The smaller partition coefficient for ethylbenzene onto diluvium red soils was resulted from the sieving effect of soils and the smaller specific interaction between them. The former affected seriously by the physical structure such as pore size distribution and pore shape. The latter related closely to the chemical nature of adsorbate and soils. But all of these interpretations need further study to be clarified clearly.

Acknowledgment. The authors gratefully acknowledge the financial support of the National Science Council, $R$. O. C., (Contract No.: NSC 83-0410-E002-116).

\section{Reference}

1. Sposito, G., The chemistry of soils, Oxford University Press, Inc., 1989.

2. Gregg S. J. and Sing K. S. W., Adsorption, Surface Area and Porosity, $2^{\text {nd }}$ edition, Academic Press, Inc. 1982.

3. Jaroniec, M. and Bräuer, P., "Recent Progress in Determination of Energetic Heterogeneity of Solids from Adsorption Data", Surface Science Reports, 6, 65-117, 1986.

4. Vukov, A. J. and Gray, D. G., "Adsorption of n-Alkanes on Carbon Fibers at Zero Surface Coverage", Langmuir, 4(3), 743-748, 1988.

5. López-Garzón, F. J., Pyde, M. and Domingo-Garcia, M., "Studies of the Surface Propreties of Activat Carbons by Inverse Gas Chromatography at Infinite Dilution", Langmuir, 9(2), 531-536, 1993.

6. Kamdem, D. P., Bose, S. K. and Luner, P., "Inverse Gas Chromatography Characterization of Brich Wood Meal", Langmuir, 9(11), 3039-3044, 1993.

7. Domingo-García, M., Fernández-Morales, I., López-Garzón, F. J., Moreno-Castilla, C. and Prados-Ramírez, M. 
J., "The Dynamic Adsorption of Several Hydrocarbons on Active Carbons", J. Colloid Interface Sci., 136(1), 160-167, 1990.

8. Meyer, E. F., "On Thermodynamics of Adsorption Using Gas-Solid Chromatography", J . Chem. Educ., 57(2), 120-124, 1980.

9. Nelson, D. W., Sommers, L. E. (1982). Total carbon, organic carbon, and organic matter. in Methods of soil analysis, part 2. Chemical and microbiological properties (2nd edition).

10. Wu, S.C. and Gschwend, P.M., Sorption Kinetics of Hydrophobic Organic Compounds of Natural Sediments and Soils, Environ. Sci.Technol. 20, 717-725, 1986.

11. Mc Lean, E. O. (1982). Soil pH and lime requirement. in Methods of soil analysis, part 2. Chemical and microbiological properties (2nd edition).

12. M. Th. van Genuchten and Wierenga, P. J., "Mass transfer studies in sorbing porous media. I. analytical solutions", Soil Sci. Soc. Am. J., 40(4), 473-480, 1976.

13. Rhoades, J. D. (1982). Cation exchange capacity. in Methods of soil analysis, part 2. Chemical and microbiological properties (2nd edition).

14. Greg, S. J. and Sing, K. S. W., Adsorption, surface area, and porosity, Academic Press Inc., London, 1982.

15. Fuller, E. L. Jr., and Thompson, K. A., "Chemical and Geometric Factors in Physical Adsorption/Desorption of Gas on Solids". Langmuir, 3(5), 713-721, 1987.

16. Seri-Levy, A. and Avnir, D., "Effects of Heterogeneous Surface Geometry on Adsorption", Langmuir, 9(11), 3067-3076, 1993.

17. Jagiello, J. and Schwarz, J. A., "Relationship between Energetic and Structural Heterogeneity of Microporous Carbons Determined on the Basis of Adsorption Potentials in Model Micropores", Langmuir, 9(10), 2513-2517, 1993.

18. Bandosz, T. J., Jagiello, J. and Schwarz, J. A., "Effect of Surface Chemical Groups on Energetic Heterogeneity of Activated Carbons", Langmuir, 9(10)2518-2522, 1993.

19. Keytes, B. R. and Silcox, G. D., "Fundamental Study of the Thermal Desorption of Toluene from Montmorillonite Clay Particles", Environ. Sci. Technol., 28(5), 840-849, 1994.

20. Kamdem, D. P., "Inverse gas chromatography characterization of birch wood meal", Langmuir, 9, 3039-3044, 1993. 